\title{
Efficacy of Quality of Life Therapy on Increasing Happiness in Patients with Major Depressive Disorder
}

\author{
Hossein Jenaabadi', Bahareh Azizi Nejad ${ }^{2}$, Ghazal Fatehrad ${ }^{3}$ \\ ${ }^{1}$ Faculty of Educational Sciences and Psychology, University of Sistan and Baluchestan, Zahedan, Iran \\ ${ }^{2}$ Department of Educational Science, Payame Noor University, Tehran, Iran \\ ${ }^{3}$ Department of Management and Economic, Science and Research Branch, Islamic Azad University, \\ Tehran, Iran \\ Email: hjenaabadi@ped.usb.ac.ir, ${ }^{*}$ bahareh19@gmail.com
}

Received 29 January 2015; accepted 20 February 2015; published 24 April 2015

Copyright (C) 2015 by authors and Scientific Research Publishing Inc.

This work is licensed under the Creative Commons Attribution International License (CC BY). http://creativecommons.org/licenses/by/4.0/

(c) (7) Open Access

\begin{abstract}
Introduction: The present study sought to examine the effectiveness of quality of life therapy on increasing happiness among patients with major depression. Methods: The research followed an experimental research design with an experimental and a control group. To this end, among the statistical population of the study that consisted of all individuals with major depression disorder, 30 individuals were randomly selected and placed in two groups (experimental and control). The experimental group individually received an intervention with a trend based on quality of life improvement for 10 sessions. The control group received no such treatment. Beck's Depression Inventory and Oxford Happiness Questionnaire were used in two occasions of pretest and posttest. Data analysis was performed using descriptive statistics and multivariate analysis of covariance. Results: The results revealed that quality of life therapy reduced depression and increased happiness among the subjects on the posttest $(p<0.01)$. Conclusion: This research found two important results. First, it was revealed that quality of life therapy had high efficiency in treating depression considered as a resistant disorder to treatment. Second, it was indicated that focus on happiness in the treatment of major depression disorder can significantly help patients recover.
\end{abstract}

\section{Keywords}

Quality of Life Therapy, Happiness, Depression

\footnotetext{
${ }^{*}$ Corresponding author.
}

How to cite this paper: Jenaabadi, H., Nejad, B.A. and Fatehrad, G. (2015) Efficacy of Quality of Life Therapy on Increasing Happiness in Patients with Major Depressive Disorder. Open Journal of Psychiatry, 5, 207-213. 


\section{Introduction}

Major depression is a disorder included of a set of disabling symptoms [1]. From the diagnostic perspective, depression is one of the most widespread diagnoses in mental disorders which encompasses many individuals with different backgrounds in the form of an epidemic [2] [3]. It is predicted that in 2020 the prevalence of this disorder will reach the second global rank diagnosis for each age group as well as each gender, while less than $25 \%$ of these patients will have access to effective therapy [4]. According to DSM data, major depression is a disorder recognized with one or several periods of major depression without backgrounds of mania treatment, mixed or hypomania. A period of major depression takes at least two weeks, typically, the person is either depressed or loses her/his interest to most activities. The individual who is diagnosed with major depressive disorder should at least meet four symptoms of a list of symptoms including changes in appetite and weight, changes in sleep and activity, absence of energy, guilt feeling, difficulties in thinking and decision-making, and recurrent death and suicidal thoughts [5].

Major depression is a recurrent disease with a variety of social, economic, physical and mental consequences [6]. It significantly affects quality of life through long term pain, disruption in occupation, in education, and in domestic or interpersonal relationships, or even committing suicide [7]. It is associated with high economic loss because of disability and repeated absence [8]. Considering the disabling effects and great human, economic and social issues associated with this disorder, a variety of approaches have been designed to treat major depression. One of the mostly used therapeutic approaches is the cognitive-behavior approach. However, the problem of this type of treatment is high recurrence of the disorder after apparently successful therapy [9]. One of the suggestions about the lack of effectiveness of this approach is the absence of attention to happiness and quality of life. Nowadays, with the appearance and spread of health psychology and positive psychology, attitudes toward disorders have left the medical framework as well as the single factor model. Researchers believe that it is better to account for the development of mental disorders by defective life styles and low quality of life and therapy should be associated with revision, reformation and change in quality of life and increasing individual capabilities, exploring personal resources and new strengths and providing satisfaction of life and well-being in individuals and societies [10].

There is a consensus among researchers that the construct of quality of life consist of objective factors as well as subjective factors (internal well-being). Objective factors consist of literacy level, income level, working conditions, marital status, security, socioeconomic position, and mental indices on the basis of individuals' assessment and perception of the level of satisfaction as well as happiness etc. [11]. Therefore, an increase in happiness contributes to one of the component of quality of life (subjective component) and increases quality of life. Regarding the influence of happiness on quality of life among individuals and society and to prevent recurrence of depression, Frisch introduced a new approach through modulation of cognitive-behavior approach and positive psychology known as quality of life therapy [12].

The approach of quality of life therapy is one of the innumerable approaches in the positive psychology that supports the approach of life satisfaction to increase human happiness and quality of life. This approach combines Aaron T. Beck's cognitive approach in the clinical area, Csikszentmihalyi’s activity theory and Seligman's positive psychology. In addition to those with disorders such as depression, the group targeted by this approach contains normal and healthy individuals, who are going to experience higher levels of well-being, mental health and in general quality of life. In this approach, principles and skills are taught to help patients identify, follow and meet needs, goals and wishes in the important and valuable areas of life. Areas which are presented in this approach include: 1-Physical health, 2-Self-esteem, 3-Goals and values, 4-Job, 5-Money, 6-Game, 7-Learning, 8-Creativity, 9-Helping others, 10-Love, 11-Friends, 12-Children, 13-Relatives, 14-House and neighbors, 15-Society, 16-Wife and 17-Life in general [12].

The quality of life therapy that is mainly focused on providing happiness and life satisfaction through cognitive-behavior change in five main concepts including circumstances, attitudes, standards that we define for ourselves, importance, and other factors influencing satisfaction of life (CASIO). These are five strategies for providing satisfaction in such areas, which enhance quality of life on the basis of providing satisfaction with the distance between what the person wants and what he/she has. This model changes these five contexts and helps patients enhance their satisfaction and happiness. Moreover, this method offers principles to deal with an increase in happiness. These principles consist of positive concepts, attitude, strengths and schemas or beliefs that assist in creating stable and enduring happiness and satisfaction [12].

Research studies on measuring the effectiveness of this approach also generally suggest its high effectiveness. For example, Ghasemi found that quality of life group therapy, combined of the positive psychology and the cognitive-behavior approach, enhances indices of mental health as well as mental well-being [13]. Toghyani et al. 
also indicated that the quality of life therapy can increase positive affection and decrease negative affection and as a result can enhance male adults' mental health [14]. Padash found that quality of life therapy contributes to happiness of married men and women [15]. Abedi compared this approach to the cognitive-behavior approach among children with obsessive-compulsive disorder and their mothers and concluded that it increased satisfaction of life and quality of life of children and their mothers and also reduced their anxiety symptoms [16].

Considering the relatively low success of the current therapies in treating depression and the lack of attention to increase the level of happiness of individuals with depression and the claim of the quality of life therapy approach on increasing capabilities and happiness, this research sought to investigate the efficiency of this approach on increasing happiness of depressed individuals.

\section{Materials and Methods}

This was an experimental study with pretest-posttest including a control and an experimental group and Ethics committee approval taken. The population included all inhabitants of Zahedan with major depression disorder referred to one of the consultation centers in Zahedan. To determine the sample among the individuals with depression referred to health centers, 48 individuals were selected among those who showed willingness to participate in the research and their score on the Beck's depression scale was 13 or higher. These individuals were interviewed by a psychotherapist using a structured clinical interview. Of these, 36 individuals were diagnosed with symptoms of major depression, among which 30 individuals were randomly selected and placed in two groups (experimental and control), each including 15 individuals. The inclusion criteria included:

1. As diagnosis was done as per DSM-IV TR, a patient should have depression, meet the DSM-IV TR criteria for depression and show no co morbidity with other I disorders.

This line should be, according to me, as diagnosis was done as per DSM-IV TR.

2. The patient should not receive medication or psychotherapy for his/her current problem.

3. The problem should not be related to drug abuse or medicine use.

4. The problem should not be related to specific physical or neurological diseases.

\section{Instruments}

\subsection{Beck's Depression Inventory-Revised Form}

This instrument is a self-report 21-item questionnaire developed to assess symptoms of depression. Each of the items has 4 options which are scored from zero (mental health symptoms) to 3 (acute and deep symptoms of depression). Items indicate four degrees of depression. The total score ranges from zero to 63 and the cut-off point for screening is 13. Its designers considered scores of 10 and higher as mild depression, 20 to 28 as moderate depression, and 29 to 63 as severe depression. The questionnaire was translated into Persian and its validity was checked. Internal consistency for the BDI on Iranian students was reported $87 \%$ and its test-retest reliability was 73\% [15]. Results of Beck, Steer and Brown indicated that the questionnaire has high internal consistency [17]. Moreover, another research study reported its alpha coefficient which was $91 \%$, the correlation calculated between scores on two halves of the test was $89 \%$ and the test-retest coefficient within a week was $94 \%$.

\subsection{Oxford Happiness Questionnaire}

The scale was developed by Argyle and Lu [18]. It has 29 items. Each of the items has 4 options scored from 0 to 3. Therefore, the maximum total score is 87 . The total score ranges from 0 to 87 . Both validity and reliability of the questionnaire have been checked in various research studies. For example, Argyle and Lu calculated the reliability of this scale using the Cronbach's alpha on 347 subjects and reported that its alpha was 90\% [18]. Alipour and Norbala also conducted the same study on 132 Iranian subjects and obtained its alpha value which was 93\% [19]. Many research studies have reported that the validity of this questionnaire is appropriate [20] [21]. Francis et al. [22] and Byani [23] reported a significant correlation of $52 \%$ and $65 \%$, respectively between the results of this questionnaire and the Beck's depression questionnaire. In addition, Alipour and Norbala confirmed the reliability of the questionnaire using face validity method [19].

\subsection{Research Procedure}

In this research 30 patients diagnosed with major depression and showed no comorbidity with other I disorders 
were randomly selected. Selected subjects were randomly divided into two groups (experimental and control (waiting list group)). Afterwards, each group of subjects was asked to attend a briefing session aimed to inform subjects of the purpose of the study and obtain their consent to participate in the research. Additionally, the agreement form was completed by each patient. They were assured that all presentations of therapeutic sessions and results of the inventories will be kept confidential and no other organization or individual will have access to them and results would be presented collectively and anonymously. Considering patients convenience, the treatment sessions were scheduled with regard to their working conditions. Subjects placed in the control group were assured that the same therapy will be conducted on them after performing the research procedure. Participants answered the two mentioned inventories (pretest) in the briefing session. After the briefing session, the participants in the experimental group individually received a treatment based on the quality of life therapy in 10, 45-minute sessions. Each treatment session was conducted in a week. The control group received no such treatment. The control group did the same when the research process was fully completed. The synopsis of the therapy sessions were as follows: Session 1 (establishing relationships, describing the major depression disorder and the effect of happiness on the disorder, teaching the quality of life therapy approach to the patients, discussing 16 domains of satisfaction with life, determining the members' problem scope, homework: thinking about how we can improve our quality of life); Session 2 (reviewing the previous session homework, discussing self-esteem and its role in increasing happiness and current skills in these areas, homework: using skills in daily life especially applying the technique of BAT); Session 3 (reviewing the previous session homework, discussing and reviewing the CASIO model in self-respect, discussing health issues and presenting related skills, homework: using skills in daily life, particularly applying the technique of TAC); Session 4 (reviewing the previous session homework, discussing goals and values, discussing the principles of quality of life, explaining the principles and application of these principles to increase satisfaction, homework: using skills in daily life, especially applying the technique of DAP); Session 5 (reviewing the previous session homework, discussing friends or relatives and its role in life satisfaction, presenting relevant skills, homework: use of skills in daily life especially the techniques of writing a letter and egg basket); Session 6 (reviewing the previous session homework, discussing the role of free time in increasing happiness, presenting related skills, homework: implementing the plan or routine leisure time or recreation hobby); Session 7 (reviewing the previous session homework, discussing learning, presenting related skills, homework: use of problem-solving skills in daily life, particularly applying the technique of problemsolving); Session 8 (reviewing the previous session homework, providing positive psychology techniques to prevent recurrence, homework: providing three basic principles of happiness: inner richness, quality of time and meaning-seeking); Session 9 (reviewing the previous session homework, discussing the principles and the scope and application of the principles in the area of relationships); and Session 10 (reviewing the previous session, reviewing all therapy sessions and conclusions).

\section{Results}

In Table 1, the mean and standard deviation of the pretest and posttest on the depression and happiness inventories are demonstrated for both groups.

To test the assumptions of analysis of covariance, Box’s M statistic was used. Box's M statistic is 959.4 and F statistics is 52.1. The significance level is $206.6(p<0.05)$. Therefore, it is indicated that the assumption of homogeneity of variance matrices-covariance is met. After presenting the assumptions, in order to compare the

Table 1. Mean and standard deviation of the groups on the pretest and posttest.

\begin{tabular}{|c|c|c|c|c|c|c|}
\hline \multirow{2}{*}{ Steps } & \multicolumn{3}{|c|}{ Depression } & \multicolumn{3}{|c|}{ Happiness } \\
\hline & Group & Mean & $\mathrm{SD}$ & Mean & SD & Frequency \\
\hline \multirow{3}{*}{ Posttest } & Experimental & 13.21 & 26.3 & 36.44 & 44.2 & 15 \\
\hline & Control & 15.22 & 35.3 & 28.47 & 05.1 & 15 \\
\hline & Total & 33.21 & 37.3 & 36.44 & 09.1 & 30 \\
\hline \multirow{3}{*}{ Pretest } & Experimental & 38.11 & 44.1 & 20.58 & 63.1 & 15 \\
\hline & Control & 20.20 & 70.3 & 13.48 & 15.1 & 15 \\
\hline & Total & 43.16 & 26.5 & 43.51 & 12.1 & 30 \\
\hline
\end{tabular}


groups' mean scores on the posttest, MANCOVA was used. Accordingly, the pre-test scores were controlled as the covariate and then the posttest scores were compared. To compare the posttest scores of the depression and happiness inventories, after controlling the pretest, multivariate analysis of covariance was used. Since the test shows significant differences between the dependent variables, to evaluate the effect of each of the variables, oneway ANCOVA was used. The results are presented in Table 2.

As Table 2 indicates, the difference between these two groups, regarding the level of depression on the posttest, is significant $[p<0.0001, \mathrm{f}(1,26)=30.19]$. Additionally, the difference between these two groups, considering the level of happiness on the posttest, is significant $[p<0.0001, \mathrm{f}(1,26)=27.103]$. It can be concluded that quality of life therapy reduces depression and increases happiness in individuals with major depression.

\section{Discussion and Conclusion}

The present study sought to examine the effectiveness of quality of life therapy on increasing happiness among patients with major depression. In this regard, it was revealed that quality of life therapy had high effectiveness in reducing depression and increasing happiness in individuals with major depression. The results are consistent with the results of other research studies confirming the effectiveness of quality of life therapy in reducing mental diseases and increasing happiness. For the example, the results are consistent with the results of Ghasemi who found that quality of life group therapy combined of the positive psychology and the cognitive-behavior approach enhanced indices of mental health and mental well-being [13]. Likewise, Toghyani et al. indicated that the quality of life therapy can increase positive affection and decrease negative affection and as a result can enhance male adults' mental health [14]. Moreover, Sin and Lyubomirsky suggested that positive psychotherapies can increase happiness [24]. Finally, the results are in line with Mitchell et al.'s study who found that compared to problemsolving-based psychotherapies or using placebo, positive psychotherapies increased happiness much higher [25].

To explain these results, several points should be mentioned. First, this approach has a general or universal view to life and its goals in each phase of the intervention is related to patients' general goals in life, so that patients are able to observe a direct relationship between an intervention or homework and realization of major needs, goals and demands. In addition, assessing and conceptualizing patients' difficulties and capabilities provide a universal viewpoint to life that is based on operating in sixteen areas of daily life with any psychological or physical difficulty, disorder or disability. The other reason for the effectiveness of this approach is the search for efficient goals known as goals and values. In this type of therapy, a part of goals and values, basic skills for controlling life and temperament control skills to prevent immobility in conformity and compatibility and to prevent chronic issues and difficulties, and to control negative emotions and organize their life in search of personal goals in important areas of life are taught to the patients. More importantly, this approach is a logo therapy aiding patients to find the most meaningful things which lead to happiness and health in the present time and in future [19].

Table 2. Results of analysis of covariance to compare the posttest scores of depression and happiness.

\begin{tabular}{|c|c|c|c|c|c|c|c|c|}
\hline Source & Dependent Variable & Sum of Squares & df & Mean Square & $\mathrm{F}$ & sig & Chi Eta & Test Power \\
\hline \multirow{2}{*}{ Pretest D } & $\mathrm{D}$ & 858.362 & 1 & 858.362 & 186.43 & 0.000 & 624.0 & 1 \\
\hline & $\mathrm{H}$ & 859.2 & 1 & 859.2 & 652.0 & 427.0 & 024.0 & 122.0 \\
\hline \multirow{2}{*}{ Pretest H } & $\mathrm{D}$ & 780.4 & 1 & 780.4 & 569.0 & 457.0 & 021.0 & 112.0 \\
\hline & $\mathrm{H}$ & 227.113 & 1 & 227.113 & 817.25 & 0.000 & 498.0 & 998.0 \\
\hline \multirow[b]{2}{*}{ Group } & $\mathrm{D}$ & 200.162 & 1 & 200.162 & 304.19 & 0.000 & 426.0 & 988.0 \\
\hline & $\mathrm{H}$ & 947.452 & 1 & 947.452 & 276.103 & 0.000 & 799.0 & 1 \\
\hline \multirow[b]{2}{*}{ Error } & $\mathrm{D}$ & 458.218 & 26 & 402.8 & & & & \\
\hline & $\mathrm{H}$ & 030.114 & 26 & 386.4 & & & & \\
\hline \multirow[b]{2}{*}{ Total } & $\mathrm{D}$ & 58363 & 30 & & & & & \\
\hline & $\mathrm{H}$ & 8336 & 30 & & & & & \\
\hline
\end{tabular}

D: Depression, H: Happiness. 
The main limitation of the current study was this subject that there are other studies in other disorders where quality of life therapy is used, such as Sharp (2002), Lambert (2006); therefore, there was no way to compare the obtained results with other new therapeutic approaches. Moreover, all steps were performed by the researcher, with the possibility of bias in subjects' responses to the inventories. Therefore, a comparison between different therapeutic approaches to treat major depression along with cooperation of therapists and subjects are recommended.

\section{References}

[1] Dozois, D.J. and Dobson, K.S. (2002) Handbook of Assessment and Treatment Planning for Psychological Disorders. Guilford Press, New York.

[2] Sharp, L.K. and Lipsky, M.S. (2002) Screening for Depression a Cross the Life Span: A Review of Measures for Use in Primary Care Settings. American Family Physician, 66, 1001-1008.

[3] Lambert, K.G. (2006) Rising Rates of Depression in Today’s Society: Consideration of the Roles of Effort Based Rewards and Enhanced Resilience in Day-to-Day Functioning. Neuroscience \& Biobehavioral, 30, 497-510.

http://dx.doi.org/10.1016/j.neubiorev.2005.09.002

[4] World Health Organization (2007) What Is Depression? http://www.who.int/mentalhealth/management/depression/definition/en/index.Html

[5] American Psychiatric Association (2014) Diagnostic and Statistical Manual of Mental Disorders. 4th Edition, American Psychiatric Association, Washington DC.

[6] Segal, Z.V., Williams, J.M.G. and Teasdale, J.D. (2002) Mindfulness-Based Cognitive Therapy for Depression: A New Approach to Preventing Relapse. Guilford, New York.

[7] Kaltenthaler, E., Shackley, P., Stevens, K., Beverley, C., Parry, G. and Chilcott, J.A. (2002) A Systematic Review and Economic Evaluation of Computerized Cognitive Behavior Therapy for Depression and Anxiety. Technical Report, Core Research, Alton.

[8] Spitzer, M. (2009) Thought Suppression as a Cognitive Vulnerability Factor for Depression an FMRI Study. Hanna Lo, Heilbronn.

[9] Joseph, S. and Lindley, A.P. (2006) Positive Therapy (A Meta Theory for Psychological Practice). Rutledge Press, USA.

[10] Seligman, M.E.P. and Csikszentmihalyi, M. (2010) Positive Psychology: An Introduction. American Psychologist, 55, 5-14. http://dx.doi.org/10.1037/0003-066X.55.1.5

[11] Lambert, M. and Naber, D. (2013) Current Issues in Schizophrenia: Overview of Patients Acceptability, Functioning Capacity and Quality of Life. CNS Drugs, 18, 5-17. http://dx.doi.org/10.2165/00023210-200418002-00002

[12] Frisch, M.B. (2006) Quality of Life Therapy. John Wiley \& Sons Press, New Jersey.

[13] Ghasemi, N. (2011) The Effectiveness of Quality of Life Group Therapy on Mental Health. Journal of Clinical Psychology, 10, 23-33.

[14] Toghyani, M., Kalantari, M., Amiri, S. and Molavi, H. (2014) The Effectiveness of Quality of Life Therapy on Subjective Well-Being of Male Adolescents. Procedia-Social and Behavioral Sciences, 30, 1752-1757. http://dx.doi.org/10.1016/j.sbspro.2011.10.338

[15] Padash, Z. (2011) The Effectiveness of Quality of Life Therapy on Happiness. Journal of Counseling and Family Psychotherapy, 1, 115-130.

[16] Abedi, M.R. and Vostanis, P. (2014) Evaluation of Quality of Life Therapy for Parents of Children with ObsessiveCompulsive Disorder in Iran. European Child \& Adolescent Psychiatry, 19, 605-613. http://dx.doi.org/10.1007/s00787-010-0098-4

[17] Beak, A.T., Steer, R.A. and Brown, G.K. (1996) An Inventory for Measuring Depression. JAMA Psychiatry, 4, 561571. http://dx.doi.org/10.1001/archpsyc.1961.01710120031004

[18] Argyle, M. and Lu, L. (1990) The Happiness of Extraverts. Personality and Individual Differences, 11, $1011-1017$. http://dx.doi.org/10.1016/0191-8869(90)90128-E

[19] Alipour, N. and Norbala, A. (1999) Validity and Reliability of Oxford Happiness Inventory. Journal of Thinking and Behavior, 18, 55-65.

[20] Hills, P. and Argyle, M. (2011) Happiness, Introversion-Extroversion and Happy Factors. Personality and Individual Differences, 30, 595-608. http://dx.doi.org/10.1016/S0191-8869(00)00058-1

[21] Furnham, A. and Cheng, H. (1999) Personality as a Predictor of Mental Health and Happiness in the East and West. Personality and Individual Differences, 27, 395-403. http://dx.doi.org/10.1016/S0191-8869(98)00250-5 
[22] Francis, L.J., Brown, I.B., Lester, D. and Philipchalk, R. (1998) Happiness as Stable Extraversion: A Cross-Cultural Examination of Reliability and Validity of Oxford Happiness Inventory among Students in the U.K., U.S.A., Australia and Canada. Personality and Individual Differences, 24, 167-171. http://dx.doi.org/10.1016/S0191-8869(97)00170-0

[23] Byani, A. (2006) Validity and Reliability of Happiness-Depression Scale. Journal of Science and Research in Psychology, 29, 73-83.

[24] Sin, N. and Lyubomirsky, S. (2009) Enhancing Well-Being and Alleviating Depressive Symptom with Positive Psychology Interventions: A Practice-Friendly Meta-Analysis. Journal of Clinical Psychology, 65, 467-487. http://dx.doi.org/10.1002/jclp.20593

[25] Mitchell, J., Stanimirovic, R., Klein, B. and Vella-Brodrick, D. (2014) A Randomized Controlled Trial of a SelfGuided Internet Intervention Promoting Well-Being. Computers in Human Behavior, 25, 749-760. http://dx.doi.org/10.1016/j.chb.2009.02.003 